\title{
Photo-ablation of single neurons in the fly visual system reveals neural circuit for the detection of small moving objects
}

\author{
Anne-Kathrin Warzecha, Alexander Borst and Martin Egelhaaf \\ Max-Planck-Institut für biologische Kybernetik, Tübingen (FRG) \\ (Received 14 February 1992; Revised version received 8 April 1992; Accepted 10 April 1992)
}

Key words: Relative motion; Optic flow; Neuronal circuit; Synaptic interaction

\begin{abstract}
Many animals use relative motion to segregate objects from their background [21, 26, 28, 31, 33]. Nerve cells tuned to this visual cue have been found in various animal groups, such as insects $[3,4,6,24,25]$, amphibians [32], birds [12, 13] and mammals [1, 14]. Well examined examples are the figure detection (FD) cells in the visual system of the blowfly $[6,11]$. The mechanism that tunes a particular FD-cell, the FD1-cell, to small-field motion is analyzed by injecting individual visual interneurons with a fluorescent dye and ablating them by illumination with a laser beam. In this way, it is shown that the FD1-cell acquires its specific spatial tuning by inhibitory input from an identified GABAergic cell, the ventral centrifugal horizontal ( $\mathrm{VCH}$ )-cell which is most sensitive to coherent large-field motion in front of both eyes. For the first time, the detection of small objects by evaluation of their motion parallax, thus, can be attributed to synaptic interactions between identified neurons.
\end{abstract}

The visual system of the blowfly (Calliphora erythrocephala) comprises 3 consecutive visual ganglia and is characterized by a layered columnar structure. The posterior part of the third visual ganglion is the main center of motion computation in the blowfly's brain. There, about 50 directionally selective interneurons with large receptive fields can be identified individually by their anatomical structure and functional properties [18]. All of these so-called tangential cells acquire their motion sensitivity by spatially integrating with their extended dendritic trees over retinotopically organized local motion detectors (for review see ref. 2). The responses of a particular tangential cell, the figure detection (FD)1-cell in the right half of the brain, to various motion stimuli were determined by extracellular recording techniques (for details see ref. 6) and are shown in Fig. 1 after the spontaneous activity was subtracted. Square-wave gratings moving horizontally with a constant velocity were generated on two CRT-screens mounted in front of the fly's eyes. The right screen was subdivided along its horizontal axis in two areas, with the frontal part corresponding to the stimulus area where small-field motion was presented to the fly. The FD1-cell responds best to front-to-back motion in the fronto-lateral visual field and prefers objects that are relatively small $\left(5^{\circ}-40^{\circ}\right.$ angular size) as com-

Correspondence: A.-K. Warzecha, Max-Planck-Institut für biologische Kybernetik, Spemannstraße 38, W-7400 Tübingen, FRG. pared with the fly's panoramic visual field. The FDl-cell responds only weakly to more extended motion stimuli. Its activity is smallest or may be even completely suppressed during coherent rotatory large-field motion in front of both eyes as is induced on the eyes when the animal turns about its vertical body axis (Fig. 1) [6]. Therefore, the FD1-cell was proposed to be inhibited by a cell most sensitive to binocular large-field motion [7].

Owing to its functional properties, the ventral centrifugal horizontal ( $\mathrm{VCH}$ )-cell is appropriate to act as largefield inhibitor of the FD1-cell. Since the VCH-cell responds to motion mainly with graded membrane potential changes $[5,16]$, it was recorded intracellularly with $40-50 \mathrm{M} \Omega$ electrodes filled with $3 \%$ Lucifer yellow $\mathrm{CH}$ (Sigma) (for details of the methods, see ref. 10). The VCH-cell responds best during binocular rotatory largefield motion $[5,15,16]$, i.e. when the inhibition of the FD1-cell is strongest (Fig. 1). As is suggested by immunohistochemical labelling, the VCH-cell is GABAergic $[20,23]$ and, thus, an inhibitory element. Recent pharmacological experiments revealed that the FD1-cell's specific tuning to small-field motion can be blocked by GABA-antagonists [9, 34].

To find out whether the VCH-cell is indeed the largefield inhibitor of the FD1-cell, we employed the photoinactivation technique. This method was originally developed for dissecting out single neurons from small circuits of neuronal motor pattern generators in the lobster 

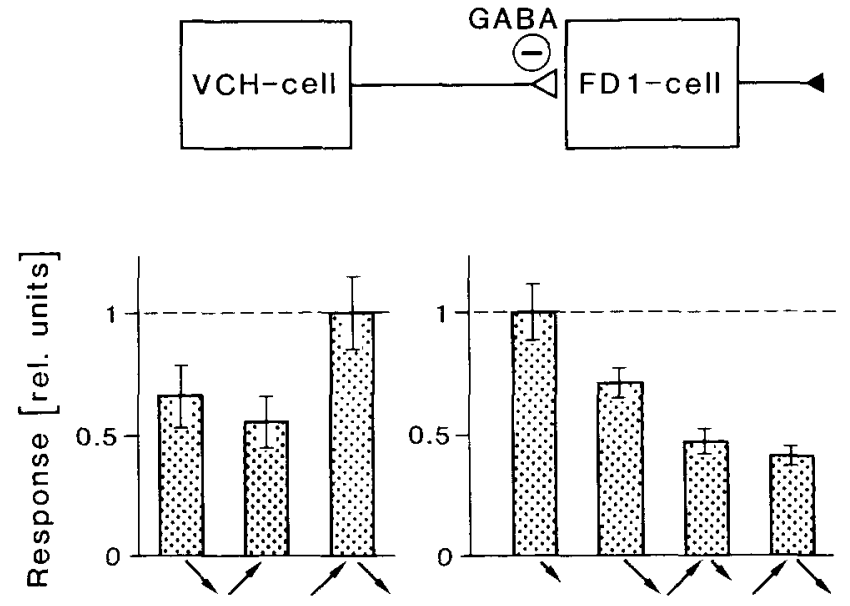

Fig. 1. Schematic diagram of the proposed mechanism responsible for tuning the FDl-cell to small-field and relative motion. The FDl-cell and its proposed inhibitory input element (VCH-cell) are illustrated by boxes. The inhibitory GABAergic synapse is represented by the open triangle. The sensitivity of the FD1-cell in the right half of the brain of the blowfly (Calliphora erithrocephala) to small-field and large-field motion is illustrated by the bars below the schematic FDl-cell. The normalized mean spike frequency responses and S.E.M.s obtained from 5 flies and a total of 25 stimulus presentations are displayed for small-field motion either alone or together with large-field motion in front of the ipsilateral eye, the contralateral eye or both eyes, respectively. The stinulus conditions are indicated by the arrows below the response bars. The normalized graded membrane potential changes of the VCH-cell to the same types of large-field motion are shown underneath the schematic VCH-cell. The data are averages from 6 flies and a total of 95 stimulus presentations. Stimulus conditions for FDl-cell recording: position of the center of the screen (azimuth, elevation with the long axis and the equatorial plane of the head corresponding to $0^{\circ}$. $\left(0^{\circ}\right)$ : left monitor: $-45^{\circ}, 0^{\circ}$; right monitor: $+25^{\circ}, 0^{\circ}$. Size of the monitors (horizontal, vertical): $68^{\circ}, 81^{\circ}$. Horizontal size of the small-field stimulus: was chosen to obtain optimal responses and amounted to either $13^{\circ}$ or $20^{\circ}$. Spatial wavelength: $7.8^{\circ}$. Temporal frequency: $2 \mathrm{~Hz}$. Contrast: $92.5 \%$. Stimulus conditions for VCH-cell recording: position of the center of the screen (azimuth, elevation): left screen: $-48^{\circ} .0^{\circ}$ : right screen: $+48^{\circ}, 0^{\circ}$. Size of the screens (horizontal, vertical): $48^{\circ}$. $35^{\circ}$. Spatial wavelength: $12^{\circ}$. Temporal frequency: $2 \mathrm{~Hz}$. Contrast: $20 \%$.

$[22,30]$ and was recently applied in the mechanosensory and auditory system of crickets $[19,29]$. The cell to be inactivated was iontophoretically filled with a saturated solution of 6-carboxy-fluorescein (Sigma) in $1 \mathrm{M}$ potassium acetate ( -1.7 to $-4 \mathrm{nA} ; 11-45 \mathrm{~min})$. Since the large motion sensitive neurons of the blowfly have an almost planar dendritic tree lying close to the surface of the brain [17] the injected cell can be exposed in vivo to laser illumination. This was done for about $2 \mathrm{~min}$ with a laser beam, after the FD1-cell was characterized. With a diameter of approximately $0.5 \mathrm{~mm}$, the laser beam covered most of the third visual ganglion (Argon Laser ILT Model 5425, Ion Laser Technology, $25 \mathrm{~mW}$ ). During laser illumination the preparation could be observed through a dissection microscope (Zeiss, OMPl) fitted
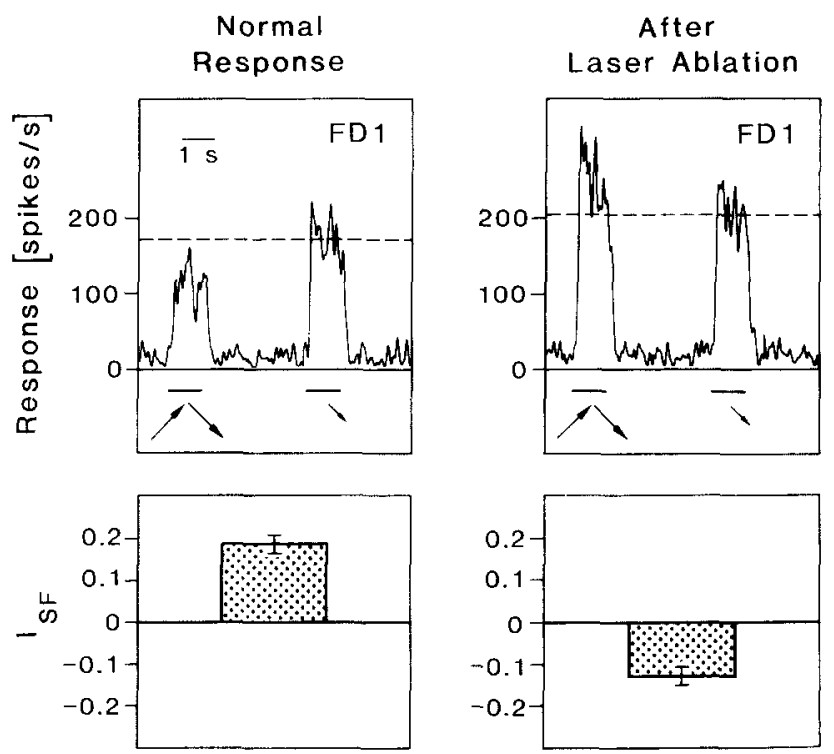

Fig. 2. Elimination of the specific sensitivity of the FDI-cell to smallfield motion by photo-ablation of the VCH-cell. Upper diagrams: spike frequency histograms of the responses to small-field motion and rotatory binocular large-field motion (stimulus conditions as indicated by the arrows underneath the response traces) before and 4 min after photo-inativation of the VCH-cell. The responses were averaged for 5 consecutive stimulus presentations. The mean response of the FDl-cell during small-field motion is indicated by the hatched line. Bottom diagrams: averaged normalized selectivity for small-field motion of the FDI-cell before and after photo-inactivation of the VCH-cell. The selectivity index for small-field motion is given by the difference between the responses to small-field and binocular large-field motion divided by their sum. For each fly. the mean responses before and after photoinactivation were determined from 15-100 consecutive stimulus presentations, depending on the stability of the record. From the selectivity indices obtained from 4 animals the means and S.E.M. were determined. Visual stimulus conditions were slightly modified as compared with that specified in the legend of Fig. I. To have a larger ipsilateral stimulus field two monitors were mounted in front of the right eye, onc above the other. Position of the center of the sereen (azimuth, elevation): left monitor: $-59^{\circ},-6^{\circ}$ : upper right monitor: $+24^{\circ},+44^{\circ}$ : lower right monitor: $+24^{\circ},-36^{\circ}$. Sizes of the monitors (horizontal, vertical): left: $60^{\circ} .50^{\circ}$ : upper right: $55^{\circ}, 41^{\circ}$ : lower right: $57^{\circ}, 45^{\circ}$. Horizontal size of the small-field stimulus: $32^{\circ}$ or $44^{\circ}$. Spatial wavelength: $12^{\circ}$. Temporal frequency: $2 \mathrm{~Hz}$. Contrast: $81 \%$.

with an orange filter (Schott, OG 590). The photo-inactivation technique kills only the injected cell leaving the response properties of other nerve cells unaffected [22]. This selectivity was confirmed by irradiating the blowfly's third visual ganglion with the laser beam and recording simultaneously the responses of motion sensitive neurons that had not been filled before with the fluorescent dye. In contrast, cells containing dye became depolarized during laser irradiation and no longer responded to visual stimulation.

In a total of 9 experiments one of three identified interneurons (equatorial horizontal (HSE) cell, dorsal centrifugal horizontal $(\mathrm{DCH})$ cell, ventral centrifugal hori- 
zontal ( $\mathrm{VCH})$ cell) in the blowfly's third visual ganglion was individually filled with 6-carboxy-fluorescein. All these cells respond best to rotatory binocular large-field motion [18] and, thus, could play a role in the circuit tuning the FD1-cell to small-field and relative motion. Then the FD1-cell was probed and, after characterization of its normal responses to large-field and small-field motion, the injected cell was killed. Photo-inactivation of neither the HSE-cell nor the DCH-cell significantly affects the tuning of the FD1-cell to small moving objects. In contrast, photo-inactivation of the $\mathrm{VCH}$-cell alters the response profiles of the FD1-cell considerably (Fig. 2). Whereas it responds with a larger spike frequency during small-field than during large-field motion before photo-inactivation, the spike frequency to large-field motion increases after the VCH-cell has been killed and now becomes somewhat larger than the spike frequency induced by small-field motion. The bottom diagrams of Fig. 2 illustrate the mean normalized differences between the responses of the FD1-cell to large-field and smallfield motion, respectively; before photo-inactivation the difference is significantly larger than zero $(P<0.0005$; Student's $t$-test); after photo-inactivation it is smaller than zero $(P<0.001)$. These data reveal that ablation of the VCH-cell eliminates the tuning of the FDl-cell to small objects moving relative to their background. Hence, from the set of visual interneurons in the fly's brain which possess the appropriate direction selectivity, the VCH-cell appears to be the only one that inhibits the FD1-cell and, thus, is responsible for the specific tuning of the FD1-cell to small-field and relative motion.

To our knowledge, the present laser ablation experiments are the first successful attempt to elucidate, on the basis of synaptic interactions between identified interneurons, the neuronal mechanism that tunes a visual interneuron to relative motion of comparatively small objects. This appears to be all the more interesting as we know the functional context of this circuit. By comparing behavioral responses of tethered flies with the response characteristics of the FD1-cell, the FD1-cell has been concluded to play a decisive role in discriminating moving objects from their background and mediating orientation turns towards them $[7,8,11,27]$. Hence, the circuit established in the present study is one of the very few examples where it has been possible to link visual orientation behavior to network interactions at the cellular level.

1 Allman, J., Miezin, F. and McGuinness, E., Direction- and velocityspecific responses from beyond the classical receptive field in the middle temporal visual area (MT), Perception, 14 (1985) 105-126.

2 Borst, A. and Egelhaaf, M., Principles of visual motion detection, Trends Neurosci., 12 (1989) 297-306.
3 Collett, T.S., Visual neurons in the anterior optic tract of the privet hawk moth, J. Comp. Physiol. A, 78 (1972) 396- 433.

4 Collett, T.S. and King, A.J., Vision during flight. In G.A. Horridge (Ed.), The Compound Eye and Vision of Insects, Clarendon, Oxford, 1975 , pp. 437-466.

5 Eckert, H. and Dvorak, D.R., The centrifugal horizontal cells in the lobula plate of the blowfly, Phaenicia sericata, J. Insect. Physiol., 29 (1983) 547-560.

6 Egelhaaf, M., On the neuronal basis of figure-ground discrimination by relative motion in the visual system of the fly. II. FigureDetection Cells, a new class of visual interneurons, Biol. Cybern., 52 (1985) 195-209.

7 Egelhaaf, M., On the neuronal basis of figure-ground discrimination by relative motion in the visual system of the fly. III. Possible input circuitries and behavioural significance of the FD-cells, Biol. Cybern., 52 (1985) 267-280.

8 Egelhaaf, M., Visual afferences to flight steering muscles controlling optomotor responses of the fly, J. Comp. Physiol. A, 165 (1989) 719-730.

9 Egelhaaf, M., How do fly FD-cells acquire their sensitivity to smallfield motion, Naturwissenschaften, 77 (1990) 182-185.

10 Egelhaaf, M., Borst, A. and Reichardt, W., Computational structure of a biological motion detection system as revealed by local detector analysis, J. Opt. Soc. Am. A, 6 (1989) 1070-1087.

11 Egelhaaf, M., Hausen, K., Reichardt, W. and Wehrhahn, C., Visual course control in flies relies on neuronal computation of object and background motion, Trends Neurosci., 11 (1988) 351-358.

12 Frost, B.J. and Nakayama, K., Single visual neurons code opposing motion independent of direction, Science, 220 (1983) 744-745.

13 Frost, B.J., Scilley, P.L. and Wong, S.C.P., Moving background patterns reveal double-opponency of directionally specific pigeon tectal neurons, Exp. Brain Res., 43 (1981) 173-185.

14 Grünau, M. von and Frost, B.J., Double-opponent-process mechanism underlying RF-structure of directionally specific cells of cat lateral suprasylvian visual area, Exp. Brain Res., 49 (1983) 8492.

15 Hausen, K., Struktur, Funktion und Konnektivität bewegungsempfindlicher Interneurone im dritten optischen Neuropil der Schmeissfliege Calliphora erythrocephala, Doctoral Dissertation, University of Tübingen, 1976.

16 Hausen, K., Functional characterization and anatomical identification of motion sensitive neurons in the lobula plate of the blowfly Calliphora erythrocephala, Z. Naturforsch., 31C (1976) 629-633.

17 Hausen, K., The lobula-complex of the fly: structure, function and significance in visual behaviour. In M.A. Ali (Ed.), Photoreception and Vision in Invertebrates, Plenum, 1984, pp. 523-559.

18 Hausen, K. and Egelhaaf, M., Neural mechanisms of visual course control in insects. In D. Stavenga and R. Hardie (Eôs.), Facets of Vision, Springer, Berlin, 1989, pp. 391-424.

19 Jacobs, G.A. and Miller, J.P., Functional properties of individual neuronal branches isolated in situ by laser photo-inactivation, Science, 228 (1985) 344-346.

20 Meyer, E.P., Matute, C., Streit, P. and Nässel, D.R., Insect optic lobe neurons identifiable with monoclonal antibodies to GABA, Histochemistry, 84 (1986) 207-216.

21 Miles, F.A. and Kawano, K., Visual stabilization of the eyes, Trends Neurosci., 10 (1987) 153-158.

22 Miller, J.P. and Selverston, A.I., Rapid killing of single neurons by irradiation of intracellularly injected dye, Science, 206 (1979) 702704.

23 Nässel, D.R., Neurotransmitters and neuromodulators in the insect visual system, Progr. Neurobiol., 37 (1991) 179-254. 
24 Olberg, R.M.. Object- and self-movement detectors in the ventral nerve cord of the dragonfly, J. Comp. Physiol., 141 (1981) 327-334.

25 Olberg, R.M.. Identified target-selective visual interneurons descending from the dragonfly brain, J. Comp. Physiol., 159 (1986) $827-840$.

26 Regan, D. and Beverley, K.I., Figure-ground segregation by motion contrast and by luminance contrast, J. Opt. Soc. Am. A, 1 (1984) $433-442$.

27 Reichardt, W., Egelhaaf, M. and Guo, A., Processing of figure and background motion in the visual system of the fly, Biol. Cybern., 61 (1989) 327-345.

28 Reichardt, W., Poggio, T. and Hausen, K., Figure-ground discrimination by relative movement in the visual system of the fly. II: Towards the neural circuitry, Biol. Cybern., 46 (Suppl.) (1983) 1-30.

29 Selverston, A.I., Kleindienst, H.-U. and Huber, F., Synaptic connectivity between cricket auditory interneurons as studied by selective photo-inactivation. J. Neurosci., 5 (1985) 1283-1292.
30 Selverston, A.I. and Miller, J.P., Mechanisms underlying pattern generation in lobster stomatogastric ganglion as determined by selective inactivation of identified neurons. I. Pyloric System, J. Neurophysiol., 44 (1980) 1102-1120.

31 Srinivasan, M.V., Lehrer, M. and Horridge, G.A., Visual figureground discrimination in the honeybee: the role of motion parallax at boundaries, Proc. R. Soc. Lond. Ser. B., 238 (1990) 331-350.

32 Tsai, H.-J., Response of toad's tectal neurons to in-phase and antiphase movements of object and textured background, J. Comp. Physiol. A, 167 (1990) 857-863.

33 van Doorn, A.J. and Koenderink, J.J., Visibility of movement gradients, Biol. Cybern., 44 (1982) $167 \ldots 175$

34 Warzecha, A.-K., Egelhaaf, M. and Borst, A., Neuronal mechanism underlying tuning to small-field stimuli of motion sensitive cells in the blowfly. In N. Elsner and H. Penzlin (Eds.), Synapse Transmission - Modulation, Thieme, Stuttgart, 1991, p. 264. 